\title{
Immunological and histological study of temporal arteries
}

\author{
J. R. PARK AND B. L. HAZLEMAN
}

From the Department of Rheumatology, Addenbrooke's Hospital, Hills Road, Cambridge

SUMMARY Sixty-four temporal arteries were studied. 36 were from patients with clinically actigूe temporal arteritis or polymyalgia rheumatica; 22 showed histological changes of temporal arteritig, 12 of which were in an active stage. 28 arteries, none of which showed histological changes, weixe taken at necropsy or from patients with unrelated disease.

Extracellular immunoglobulin and complement deposition was seen in the artery biopsies showigh active arteritis and in 1 of the 10 biopsies with inactive arteritis. There was no immunoglobulin $0 \mathrm{r}$ complement deposition in the 14 patients with clinically active temporal arteritis and/or polymyalgia rheumatica, but with a normal artery biopsy. Patients with clinically active temporal arteritis wefe more likely to have a positive biopsy. Our results support the suggestion that the immune deposition is concurrent with an active histologically proven arteritis. Immunofluorescent examination does not appear to be a better diagnostic test than histological examination.

There is an increasing tendency to consider temporal arteritis and polymyalgia rheumatica as closely related conditions and it is difficult to maintain a practical distinction between them by clinical or histological criteria (Hazleman, 1976). Patients originally suffering from polymyalgia rheumatica have later had symptoms of cranial arteritis and in a number of patients with typical myalgia and no symptoms from the temporal region, biopsies have shown arteritic changes. Fauchald et al. in 1972 found that $40 \%$ of patients with myalgia alone had a positive biopsy and of those with a proven arteritis $18 \%$ did not have myalgia.

However, diagnosis may prove difficult and despite a typical pattern of musculoskeletal symptoms and the presence in many of significant systemic features, there is often considerable delay before diagnosisa mean of 6.2 months in one study (Mowat and Hazleman, 1974). Although the erythrocyte sedimentation rate is usually greatly raised in almost all patients and can be regarded as a key diagnostic test, it can be normal in patients with active disease proven by biopsy (Bruk, 1967; Roux, 1954). Temporal artery biopsy is therefore a most important diagnostic procedure; however, the arteritis is not uniform and the small section of temporal artery taken at biopsy may well be normal.

Accepted for publication September 10, 1977 Correspondence to Dr B. L. Hazleman
Liang et al. (1974) demonstrated certain pattegins of immunoglobulin deposition in the tempogal arteries of patients with histologically positike temporal arteritis. However, only 3 patients witha positive biopsy were studied. It was therefore fellt that a further study was necessary, the aims be (1) to ascertain the incidence of arteritis in 64 temporal artery biopsies; (2) to assess the pattems of immunoglobulin and complement deposition; and (3) to establish the diagnostic value of immunofluorescence.

\section{Histology}

The temporal artery biopsy was divided into t half being processed in the routine histology laboratory. Biopsies with abnormal histology we classified as being either in an active or inactive stage. Active arteritis: showing infiltration with lymplobcytes, plasma cells, and multinucleate giant cells In the media, and a disrupted internal elastic lamina (IEL). Inactive arteritis: showing a swollen a disrupted IEL with thickened intima but lacking inflammatory cell infiltrate.

\section{Patients}

Temporal arteries were biopsied in 36 patie Bts $_{\text {ts }}$ presenting with symptoms of polymyalgia rhemmatica or temporal arteritis over an 18-month 
period. Disease activity was assessed at presentation and graded 1-4 (mild-active).

Diagnosis of polymyalgia was based on clinical criteria (Dixon, 1969; Hunder et al., 1969). The clinical details are summarised in Table 1. Diagnosis of temporal arteritis was supported in all cases by a temporal artery biopsy. All patients had a negative test for rheumatoid factor. None of the patients studied was on corticosteroids at the time of biopsy, though 3 patients in each group had previously been treated.

Seventeen biopsies were from patients with an unrelated pathology (Table 2). 11 control arteries were obtained at necropsy from patients who had died of unrelated disease (4 carcinomatosis, 3 chronic bronchitis, 4 myocardial infarction) with no previous evidence of temporal arteritis.

Table 1 Clinical details of patients presenting with symptoms of polymyalgia rheumatica and temporal arteritis

\begin{tabular}{|c|c|c|c|}
\hline & \multicolumn{3}{|l|}{ Histology } \\
\hline & Active & Inactive & Normal \\
\hline & 12 & 10 & 14 \\
\hline \multicolumn{4}{|l|}{ Age (years) } \\
\hline $\begin{array}{l}\text { Mean } \\
\text { Range }\end{array}$ & $\begin{array}{l}71 \\
65-75\end{array}$ & $\begin{array}{l}67 \\
61-79\end{array}$ & $\begin{array}{l}70 \\
59-80\end{array}$ \\
\hline \multicolumn{4}{|l|}{ Sex } \\
\hline $\mathbf{M}$ & 5 & 2 & 3 \\
\hline $\mathbf{F}$ & 7 & 8 & 11 \\
\hline \multicolumn{4}{|l|}{ Duration of symptoms } \\
\hline before biopsy (m) & 13 & 14 & 6 \\
\hline Range & $1-72$ & $1-96$ & $1-36$ \\
\hline Headache & 9 & 6 & 3 \\
\hline Visual symptoms & 3 & 2 & 3 \\
\hline Myalgia & 5 & 8 & 14 \\
\hline $\begin{array}{l}\text { Normal artery on clinical } \\
\text { examination }\end{array}$ & 5 & 5 & 14 \\
\hline $\mathrm{Hb}(\mathrm{g} / \mathrm{dl})$ & & & \\
\hline Mean & $10 \cdot 5$ & $12 \cdot 3$ & $12 \cdot 5$ \\
\hline Range & $6 \cdot 6-13 \cdot 2$ & $10 \cdot 8-13 \cdot 9$ & $9 \cdot 3-14 \cdot 8$ \\
\hline \multicolumn{4}{|l|}{$\operatorname{ESR}(\mathrm{mm} / \mathrm{h})$} \\
\hline Mean & 96 & 83 & 58 \\
\hline Range & $26-138$ & $7-130$ & $16-136$ \\
\hline
\end{tabular}

Table 2 Diseases in controls

\begin{tabular}{ll}
\hline Diagnosis & $n$ \\
\hline 'Viral myalgia'* & 5 \\
Transient ischaemic attacks & 4 \\
Polyarteritis nodosa & 3 \\
Cervical spondylosis & 3 \\
Polymyositis & 1 \\
Carcinoma of larynx & 1 \\
Post mortem & 11 \\
Total & 28 \\
\hline
\end{tabular}

*Certain features atypical of polymyalgia rheumatica. Symptoms settled within 3 months with no recurrence.

\section{Method}

Immunofluorescence was carried out before the histology results were known. The arteries were washed in phosphate-buffered saline (PBS) and placed on a $12 \mathrm{~mm}$ diameter circular millipore membrane (Millipore $0.22 \mu \mathrm{m}$ pore size). The membrane was then inserted into a $5 \mathrm{ml}$ polytube, orientated so that transverse sections of artery would be obtained, and covered with a $7 \%(w / v)$ gelatin in $0.9 \%$ sodium chloride containing $0.05 \%$ sodium azide. The tubes were dipped in liquid nitrogen for 90 seconds, capped, and placed at $-20^{\circ} \mathrm{C}$ for storage. $5 \mu \mathrm{m}$ cryostat sections were cut at several levels and placed on glass microscope slides, which had been washed overnight in concentrated nitric acid.The sections were rapidly air dried, fixed for 10 minutes in $4 \%$ formaldehyde in PBS freshly prepared from paraformaldehyde (Glauert, 1965), and washed in PBS (30 minutes). Sections were treated with $50 \mu 1$ of reagent, incubated in a moist chamber $(30 \mathrm{~min})$, and then washed $(30 \mathrm{~min})$. Slides were rinsed in distilled water before mounting under coverslips in Trisglycerol (9 parts glycerol, 1 part $0.2 \mathrm{M}$ Tris buffer $\mathrm{pH} 8 \cdot 7$ ).

Ethidium bromide $(5-50 \mu \mathrm{g} / \mathrm{ml}$ in $5 \%$ EDTA), which selectively stains nuclei, was used as a counterstain to assist location of the fluorescent material. The sections were examined using a standard incident light fluorescence microscope system. Photographs were taken using a high speed Ektachrome ASA 160 (daylight) film.

\section{REAGENTS}

Direct immunofluorescence was carried out using specific antibodies to human IgG, IgA, IgM, and the third component of complement all labelled with fluorescein isothiocyanate (FITC) (Dako).

Indirect immunofluorescence was carried out using $F\left(a b^{\prime}\right)_{2}$ preparations of rabbit antiserum to human IgG $F\left(\mathrm{ab}^{\prime}\right)_{2}$, normal rabbit serum IgG and FITC-labelled pig antiserum to rabbit IgG $F\left(\mathrm{ab}^{\prime}\right)_{2}$ prepared by the method of Poole et al. (1976). Before treatment of the sections, the divalent $\mathrm{F}\left(\mathrm{ab}^{\prime}\right)_{2}$ was reduced to monovalent $\mathrm{Fab}^{\prime}$ by incubation for 30 minutes in $10 \mathrm{mM}$ L-cysteine (Sigma) in PBS. The smaller Fab' molecule more easily diffuses into the tissue. Staining and washing was carried out in $5 \mathrm{mM}$ L-cysteine in PBS. Unlabelled reagents were used in blocking tests to confirm specificity of the reaction.

All reagents were tested by immunoelectrophoresis to check their specificity, and appropriate controls were carried out in each of the arteries tested. Where necessary an initial incubation with 
normal pig or sheep serum was used to reduce nonspecific binding of the FITC-labelled antisera to the tissue.

\section{Results}

Three distinct patterns of immunofluorescent staining were evident: (a) specific fluorescence in the media, (b) fluorescent stain on or adjacent to the IEL, and (c) 'nonspecific' background stain.

\section{MEDIA FLUORESCENCE}

Specific fluorescent stain was seen in the media of all patients with active histology and in one patient with inactive histology (Fig. 1). The stain was granular, varied from minute specks to larger discrete areas of fluorescence, and was not distinctly located around the nucleus. The deposits tended to be elongated parallel to the circumference of the artery and were often close to the IEL. In three arteries deposition was along the media/adventitia junction alone. In some of the sections showing this staining in the media, similar fluorescence could be observed in both the intima and adventitia of the same section.

Fig. 2 shows the number of patients showing media fluorescent staining with each of the direct immunofluorescent reagents; most arteries showed more than one class of immunoglobulin stain. The C3 component of complement was seen in all arteries that contained immunoglobulin in a similar distribution to the immunoglobulin. The presence of immunoglobulin in the intima alone was not regarded as evidence for a positive fluorescent lesion as this was seen in normal arteries, and was probably due diffusion of immunoglobulin from the blood.

The results using the indirect method we essentially the same as those using the direst method.

\section{ELASTIC FLUORESCENCE}

Linear fluorescence was demonstrated along bơ h sides of the IEL and capping the natural breaks 茄 the lamina (Fig. 3). This staining pattern occurred in $3 / 12$ patients with active histology, in $2 / 10$ wit inactive histology, and in $3 / 17$ patients with nornal histology and unrelated pathology. For this reasôn we find this staining pattern inconclusive, although it was one which Liang et al. (1974) regarded cas significant as it was found in $3 / 3$ patients with histologically active disease, in 4/12 patients wffh polymyalgia but normal histology, and in $0 \Re 0$ controls. The criteria for inclusion in the potymyalgia group may well be different in the tho studies.

\section{'NONSPECIFIC' BACKGROUND STAIN}

The background stain was seen in both controls afd arteritis patients and could be attributed to the permeability of the vessel wall to immunoglobulin a a other components of the blood increasing with a The staining could be reduced by prior incubat with normal serum, but in some cases it was quitte intense and could have masked the more granufar immunoglobulin stain of the media. Table 3 summarises the distribution of fluorescent stain patterns in the histology groups studied.

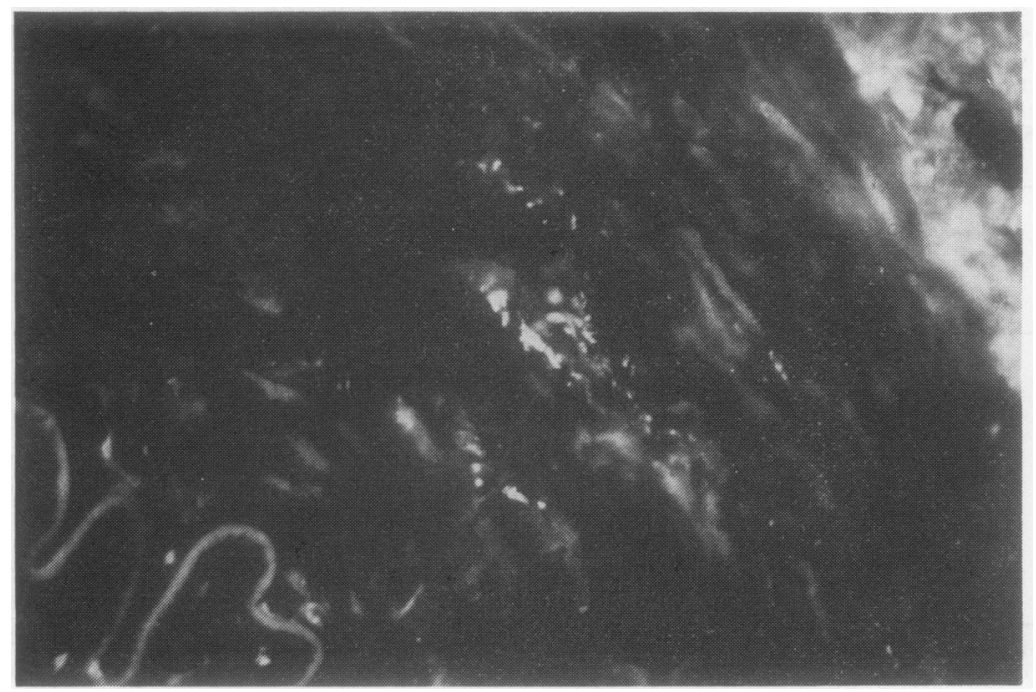

Fig. 1 Medial fluorescence in $\stackrel{\sim}{a}$ patient with clinically active temporal arteritis. The internaస elastic lamina is seen in the lover left corner. Nuclei are weakly stained with ethidium bromide.등 $\times 320$. 


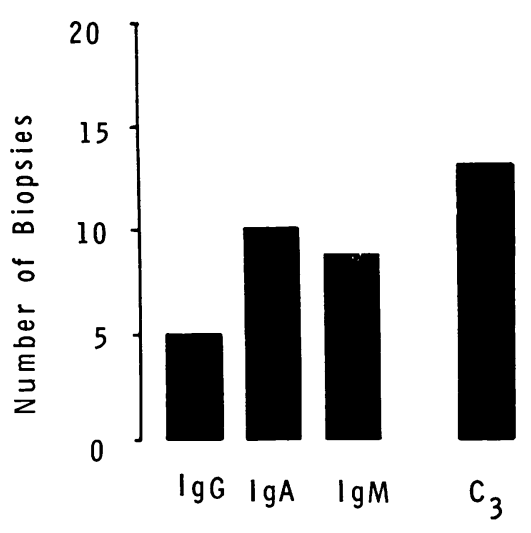

Fig. 2 Incidence of immunoglobulin and complement $C 3$ in the media of temporal arteries.

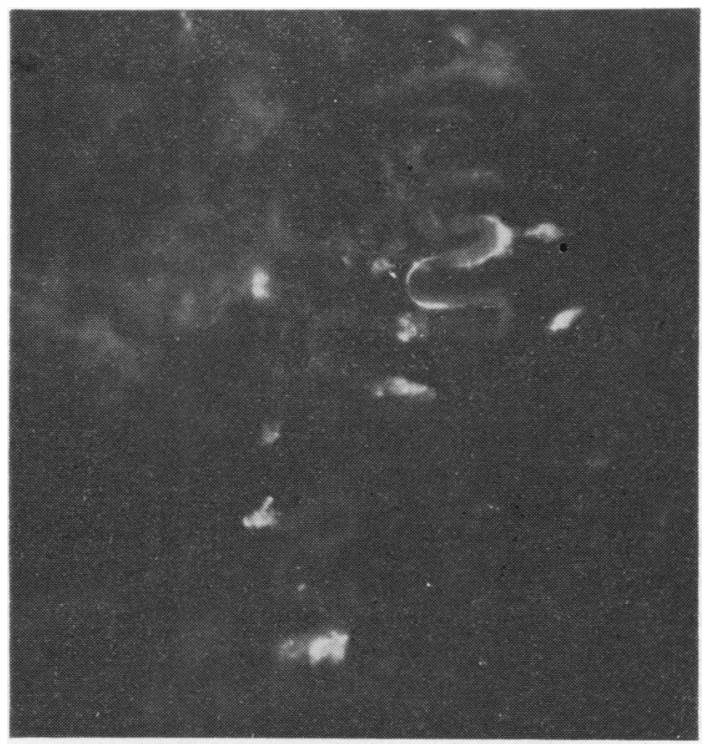

Fig. 3 Immunofluorescence on and adjacent to the internal elastic lamina in a patient with clinically active temporal arteritis. $\times 340$.

Table 3 Distribution of fluorescent staining patterns correlated with histology

\begin{tabular}{lllll}
\hline Histology & $\begin{array}{l}\text { Symptoms } \\
\text { of PMR }\end{array}$ & $n$ & $\begin{array}{l}\text { IEL } \\
\text { fluorescence }\end{array}$ & $\begin{array}{l}\text { Specific } \\
\text { media } \\
\text { fluorescence }\end{array}$ \\
\hline Active arteritis & + & 12 & 3 & 12 \\
Healed arteritis & + & 10 & 2 & 1 \\
Normal & + & 14 & 0 & 0 \\
Normal & - & 17 & 3 & 0 \\
Normal (PM & & 11 & 0 & 0 \\
$\quad$ arteries) & - & & & \\
\hline
\end{tabular}

$\mathrm{IEL}=$ internal elastic lamina.
Figs. 4 and 5 correlate clinical features, namely presence of arteritis or myalgia, and an estimate of clinical activity with the histological findings. Fig. 4 shows that $50 \%$ of patients with arteritis complained of myalgia. However, in patients with myalgia but a negative biopsy there were 3 with clinical symptoms suggestive of arteritis. Patients with active arteritis on biopsy tended to have more severe symptoms (Fig. 5), whereas patients with inactive arteritis tended to fall between these two extremes. Although it seems that there is a correlation between the
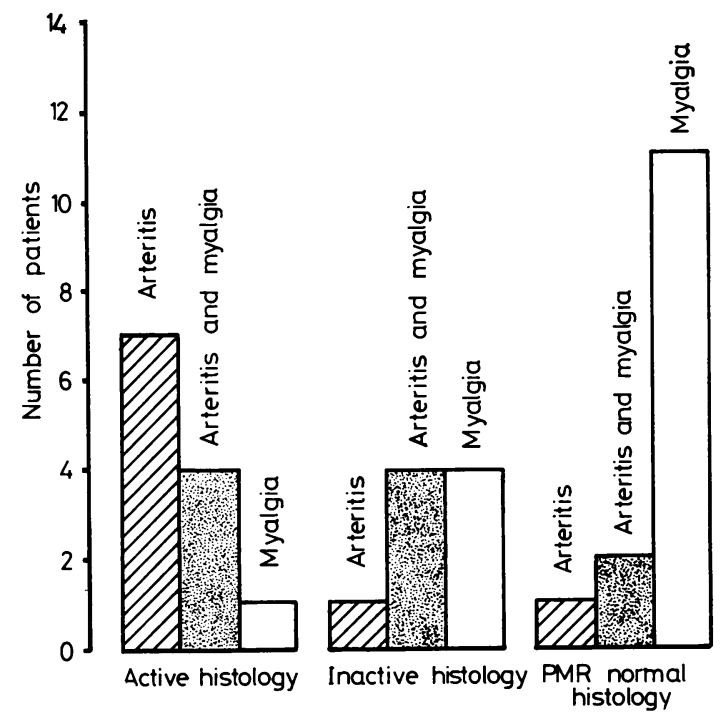

Fig. 4 Correlation of clinical symptoms of arteritis and myalgia with histology. One patient with inactive histology had no arteritis or myalgia.

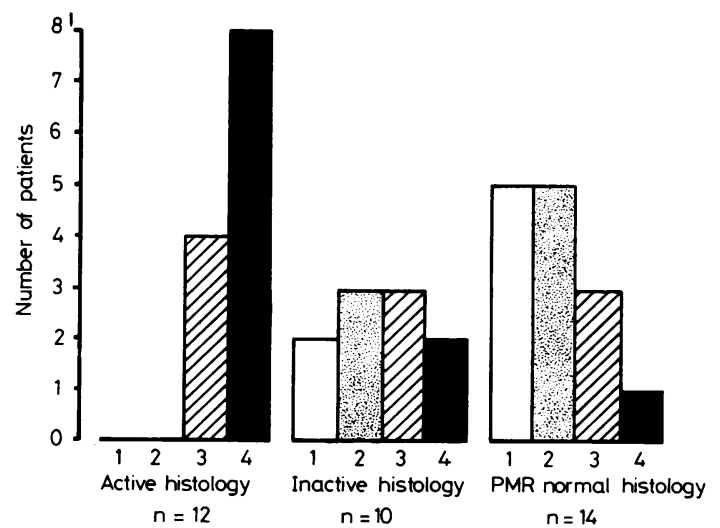

Fig. 5 Correlation of clinical activity (graded 1-4, mild to active) with histology. 
severity of symptoms and the activity of arteritis on biopsy, it should be noted that serial sections of a biopsy often show the presence of both active and inactive changes.

In no patient were autoantibodies detected and the SCAT was negative. Immunoglobulin levels fell within the normal range and there was no difference between groups.

\section{Discussion}

These studies confirm those of Liang et al. (1974) and Sauerbruch et al. (1973) and suggest that immunoglobulins are involved in the disease process of temporal arteritis. But Horowitz et al. (1977) carried out immunofluorescent staining in 12 temporal artery biopsies and detected no immunoglobulin staining, however only one biopsy showed definite arteritis. It is not possible to state whether the patterns we observed result from the passive deposition of immune complexes or from the combination of specific antibodies with antigens.

The finding of immune deposits in affected tissue is commonly thought to indicate immune-complex induced disease. However, immune deposits may be found in tissue in other situations where there is little else to suggest immune-complex disease (Sutherland et al., 1974). Conversely, the absence of immune deposits may not rule out immune complex disease, because immune complexes are removed by granulocytes within hours after injecting antigen into the skin of a sensitised animal (Cochrane et al., 1959). Immune reactants are frequently absent from vessel walls of patients with chronic vasculitis, although they can be identified during the acute necrotising stage (Conn et al 1972).

Our results can not be compared with the immunological and histological study of Waaler et al., 1976, because in their study sections fixed in $4 \%$ formaldehyde showed no activity-a treatment used in preparing our sections. Our results are similar to those of Liang et al. (1974), but we detected no specific stain within the cytoplasm, and think the stain is in an extracellular position, nor $\mathrm{do}^{-}$we attach such diagnostic" significance to staining of the IEL. This was present in 3 patients who had certain features atypical of polymyalgia rheumatica. These symptoms resolved within 3 months and on follow-up there has been no recurrence over one year.

Some recent observations have suggested a possible immunological basis for polymyalgia rheumatica and temporal arteritis. Infiltration of the IEL by mononuclear cells occurs (Parker et al., 1972). Raised circulatory immunoglobulins, especially $\operatorname{IgM}$, are found in some patients (Bacon et al., 1975). Alsפ. circulating immunoblasts have been described (Eghtedari et al., 1976). Recently increased sens $\overrightarrow{\vec{F}}$ tivity of peripheral blood lymphocytes to humat artery and muscle has been reported using lymphocyte transformation test (Hazleman et a $a$ 1975) and the histocompatibility antigen HLA was significantly more common in patients with

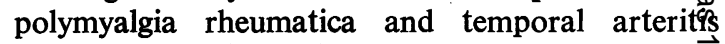
(Hazleman et al., 1977).

Histological examination of the temporal arter in an active region shows inflammatory cells ans sometimes giant cells together with swelling and disruption of the IEL. When present giant cells are often closely associated with the IEL and may show elastic fragments in their cytoplasm (Parker et a 1972). Histological changes also occur in tempora arteries with advancing age and they differ only degree from those seen in temporal arteritis. It sometimes difficult to distinguish between the $\vec{m}$ (Ainsworth et al., 1961). However, an inflammato cell infiltrate does not occur except in relationship $\vec{B}$ large plaques of atherosclerosis. Diagnosis may alse be complicated by the presence of skip lesions. These were identified in $28 \%$ of patients with tempored arteritis in a recent study (Klein et al., 1976). The found foci of arteritis as short as $330 \mu \mathrm{m}$ in length an otherwise normal biopsy. In addition, $65 \%$ of the patients with skip lesions had temporal arteries completely normal to palpation, compared to only $23 \%$ of those with continuous involvement. $\frac{9 t}{3}$ should be noted that patients with skip lesions do not have a more benign disease.

There is a close relationship between arteritis and the amount of elastic tissue present in the artery wa्d 1 (Wilkinson and Russell, 1972). Temporal arteritis may arise as an immune reaction to the IEL whieh has been damaged by advancing age (Hazleman $\& t$ al., 1975). Certainly a widespread vasculitis wou explain many of the features of polymyalgia rhegmatica and the close clinical relationship is again borne out in this study.

Our results support the idea that immune depos tion is concurrent with an active arteritis. However, the immunofluorescent study of temporal arteries does not appear to be a more sensitive guide disease state in our hands than other methods currently used.

We thank the Arthritis and Rheumatism Council for continued support; and are grateful to the physicians at Addenbrooke's Hospital who kindly referröd cases, and to the Department of Ophthalmology many of the temporal artery biopsies. We thanjk Dr R. Poole and Miss R. Hembry for helpful adviç about immunofluorescence techniques. 


\section{References}

Ainsworth, R. W., Gresham, G. A., and Balmforth, G. V. (1961). Pathological changes in temporal arteries removed from unselected cadavers. Journal of Clinical Pathology, 14, 115-119.

Bacon, P. A., Doherty, S. M., and Zuckerman, A. J. (1975). Hepatitis-B antibody in polymyalgia rheumatica. Lancet, 2, 476-478.

Bruk, M. I. (1967). Articular and vascular manifestations of polymyalgia rheumatica. Annals of the Rheumatic Diseases, 26, 103-113.

Cochrane, C. G., Weigle, W. D., and Dixon, F. J. (1959). The role of polymorphonuclear leucocytes in the initiation and cessation of the arthus vasculitis. Journal of Experimental Medicine, 110, 481-494.

Conn, D. L., McPuffie, F. C., and Dyck, P. J. (1972). Immunopathologic study of sural nerves in rheumatoid arthritis. Arthritis and Rheumatism, 15, 135-143.

Dixon, A. St. J. (1969). Polymyalgia rheumatica. Journal of the Royal College of Physicians of London, 4, 55-61.

Eghtedari, A. A., Esselinckx, W., and Bacon, P. A. (1976). Circulating immunoblasts in polymyalgia rheumatica. Annals of the Rheumatic Diseases, 35, 158-161.

Fauchald, P. Rygvold, O., and Oystese, B. (1972). Temporal arteritis and polymyalgia rheumatica. Annals of Internal Medicine, 77, 845-854.

Glauert, A. M. (1965). The fixation and embedding of biological specimens. Techniques for Electron Microscopv, pp. 166-122. Ed. by D. Kay. Blackwell, Oxford.

Hazleman, B. L. (1976). Giant cell arteritis and polymyalgia rheumatica. Modern Topics in Rheumatology pp. 126-134. Ed. by G. R. V. Hughes. Heinemann, London.

Hazleman, B. L., MacLennan, C. M., and Esiri, M. M. (1975). Lymphocyte proliferation to artery antigen as a positive diagnostic test in polymyalgia rheumatica. Annals of the Rheumatic Diseases, 34, 122-126.

Hazleman, B. L., Goldstone, A., and Voak, D. (1977). Association of polymyalgia rheumatica and giant cell arteritis with HLA-B8. British Medical Journal, 2, 989.
Horowitz, H. M., Pepe, P. F., Johnsrude, I. S., McCoy, C·, Jackson, D. C., and Farmer, J. C. (1977). Temporal arteriography and immunofluorescence as diagnostic tools in temporal arteritis. Journal of Rheumatology, 4, 76-85.

Hunder, C. G., Disney, T. F., and Ward, L. E. (1969). Polymyalgia rheumatica. Mayo Clinic Proceedings, 44, 849-875.

Klein, R. G., Campbell, R. J., Hunder, G. G., and Carney, A. A. (1976). Skip lesions in temporal arteritis. Mayo Clinic Proceedings, 51, 504-510.

Liang, G. C., Simkin, P. A., and Mannik, M. (1974). Immunoglobulins in temporal arteries. Annals of Internal Medicine, 81, 19-24.

Mowat, A. G., and Hazleman, B. L. (1974). Polymyalgia rheumatica-a clinical study with particular reference to arterial disease. Journal of Rheumatology, 1, 190-201.

Parker, F., Healey, L. A., and Wilske, K. R. (1972). Electron microscopy of giant cell arteritis: unique changes in internal elastic lamina. (Abst.) Arthritis and Rheumatism, 15, 449.

Poole, A. R., Hembry, R. M., Dingle, J. T., Pinder, I., Ring, E. F. J., and Cosh, J. (1976). Secretion and localization of cathepsin D in synovial tissues removed from rheumatoid and traumatized joints. An immunohistochemical study. Arthritis and Rheumatism, 19, 1295-1307.

Roux, J. L. (1954). Le syndrome de l'artérite temporale. Helvetia Medica Acta, 21, Suppl. 34, 1-82.

Sauerbruch, T., Stuhlinger, B., and Kaess, H. (1973). Immunhistologische Untersuchungen bei einem Fall von Riesenzellarteritis (Arteritis temporalis). Deutsche Medizinische Wochenschrift, 981, 283-284.

Sutherland, J. C., Mackham, R. V., and Mardiney, M. R. (1974). Subclinical immune complexes in the glomeruli of kidneys post mortem. American Journal of Medicine, 57, 536-541.

Waaler, E., Tönder, O., and Milde, E. J. (1976). Immunological and histological studies of temporal arteries from patients with temporal arteritis and/or polymyalgia rheumatica. Acta Pathologica et Microbiologica Scandinavica, Section A, 84, 55-63.

Wilkinson, I. M. S., and Russell, R. W. (1972). Arteries of the head and neck in giant cell arteritis. Archives of Neurology, 27, 378-391. 